\title{
AGRICULTURAL EXTENSION WORKER'S PERFORMANCE OF SOME EXTENSION ACTIVITIES IN GIZA GOVERNORATE, EGYPT
}

\author{
(Received:7.3.2010)
}

By

\author{
A.A.A. Azam \\ Department of Rural Sociology and Agriculture Extension, Faculty of Agriculture, \\ Cairo University, Giza, Egypt
}

\begin{abstract}
This study aimed to measure the level of Agricultural Extension Worker's (AEWs) performance of extension activities in the areas of planning and evaluation of extension programs, and handling farmer's interests, and to identify the contribution of some independent variables in the variation of the level of performance as a dependent variable. The study was conducted in Giza Governorate. Data were collected, by utilizing a questionnaire, through personal interviews with a sample of 79 AEWs. Frequencies, average means, standard deviations, Chi-square test, Pearsonian correlation and step-wise multiple correlation and regression analysis, were used for data presentation and analysis.

1-Medium levels of AEWs performance of extension activities, in the areas of planning and evaluation of extension programs, and handling farmers` interests, were found.

2-Statistically significant relationships (at .01 level) were found between (AEWs) performance of extension activities in the area of planning and evaluation of extension programs, and rural background. This performance was significantly related, (at .05 level), with educational qualification.

3-Statistically significant relationships (at .01 level) were found between (AEWs) performance of extensions activities in the area of planning and evaluation of extension programs, and both period of service in extension service, and degree of contact with information sources. This performance was significantly related, (at .05 level), with extension training.

4-Statistically significant relationships (at .01 level) were found between (AEWs) performance of extension activities in the area of handling farmer's interests, and: educational qualification, period of service in agriculture and period of service in extension service.

5- Extension pamphlets and extension supervisors were the most frequently utilized sources of information (as reported by around $49.4 \%$ and $44.3 \%$, successively).
\end{abstract}

Key words: agricultural extension, personnelinterviews, extension activities, performance.

$$
\begin{aligned}
& \text { أداء المرشدين الزراعيين لبعض الأنشطة الإرشادية بمحافظة الجيزة- مصر } \\
& \text { عبدالشافي احمد عزام } \\
& \text { قسم الاجتماع الريفى و الإرشاد الزر اعي ـ كلية الزراعة ـ جامعة القاهرة ـ الجيزة ـ مصر }
\end{aligned}
$$

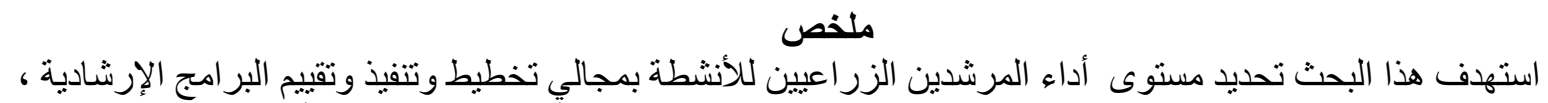

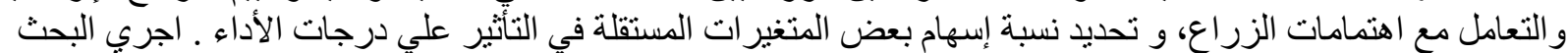

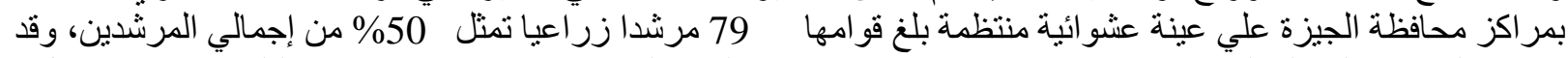

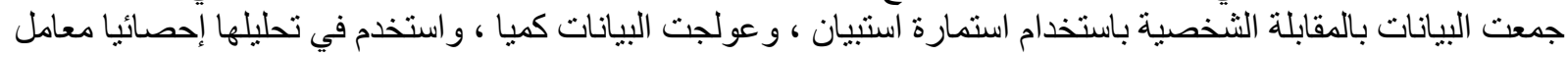

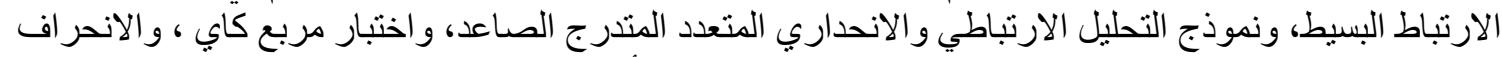

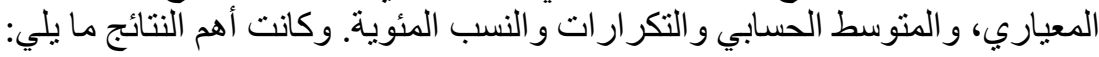


1-نبين أن مستوى أداء المبحوثين للأنشطة الإرشادية كان متوسطا وذلك فيما يختص بمجالي تخطبط وتقييم البر امج الإرشادية

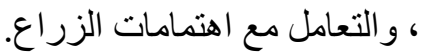

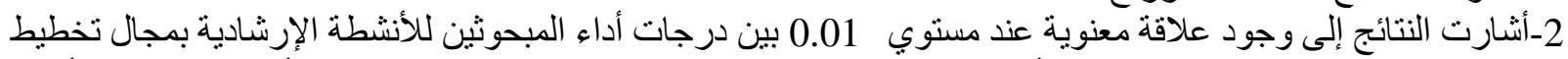

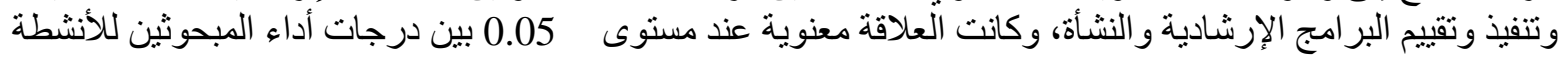

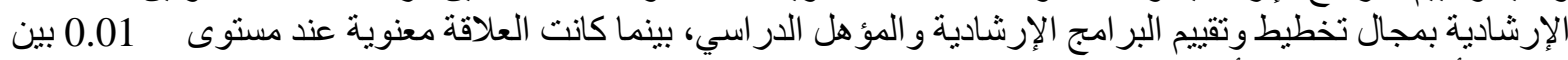

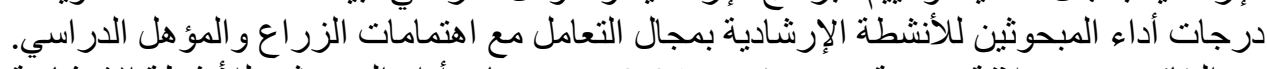

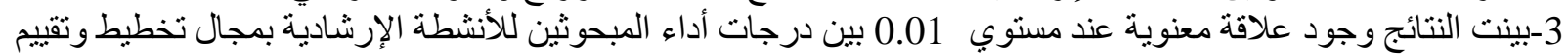

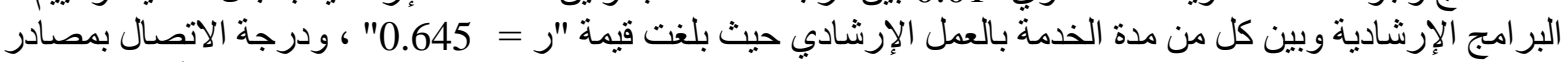

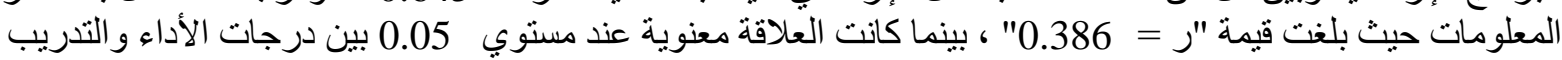

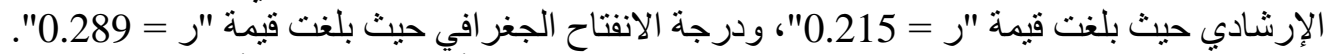

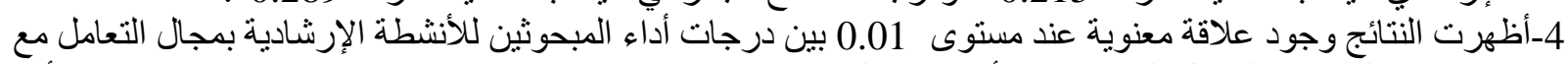

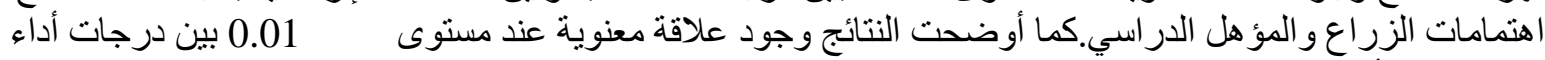

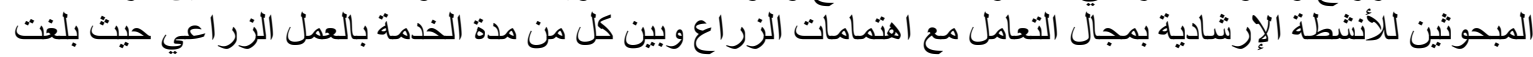

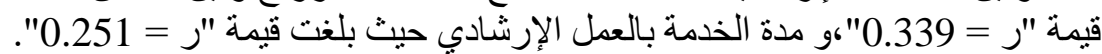

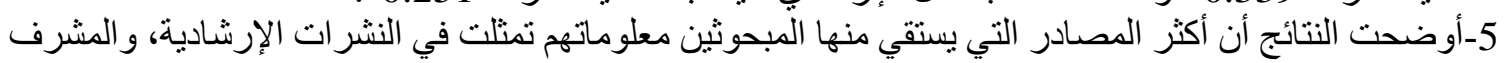

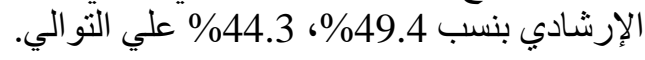

ويذكر ( الر افعي ، 1992) أن المرشد الزر اعي يقوم

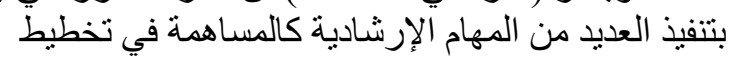

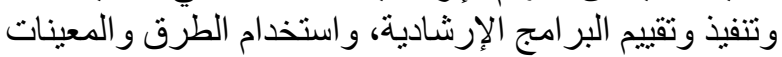

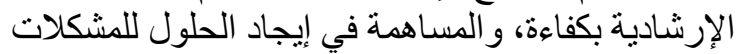

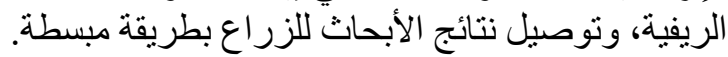

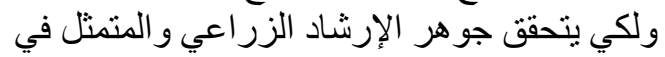

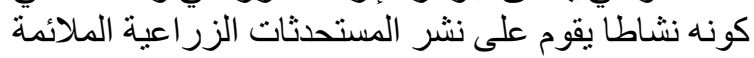

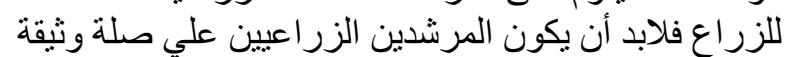

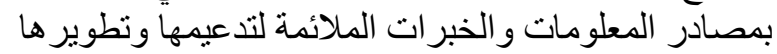

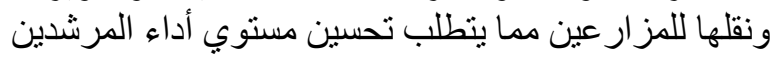

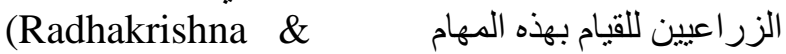
Thomson, 2007)

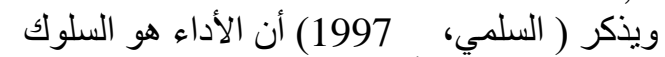

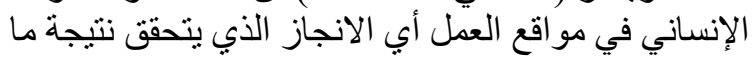

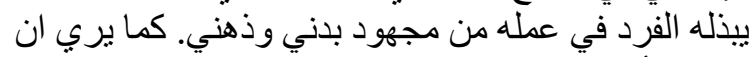

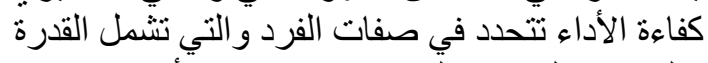

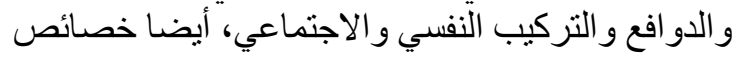

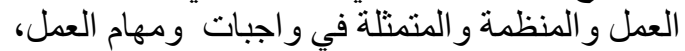

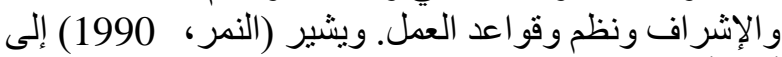

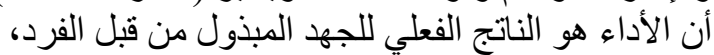

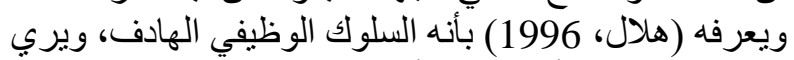

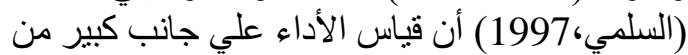

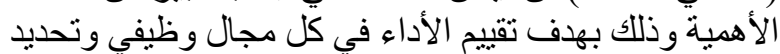

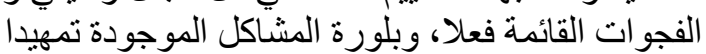

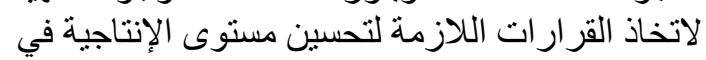

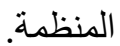

ونظر الان العمل الإرشادي الزراعي يتركز في

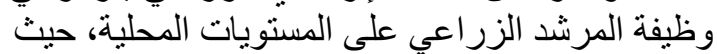

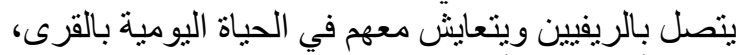

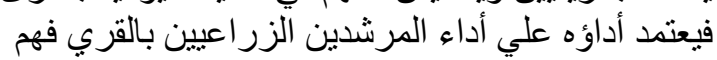

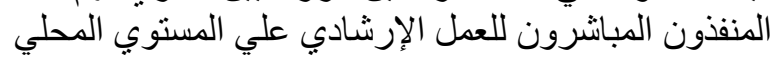

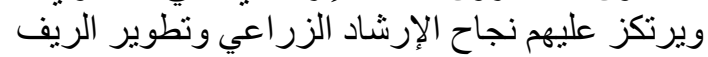

(Swanson, 1984)

\section{1. المقدمة والمشكلة البحثية}

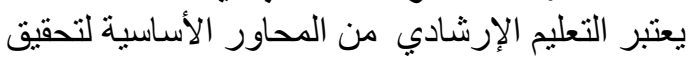

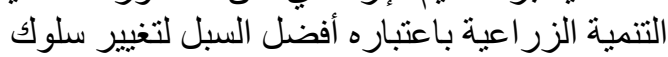

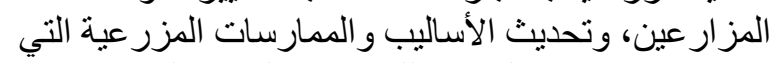

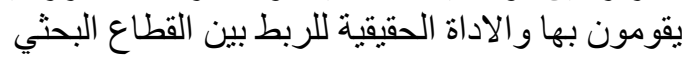

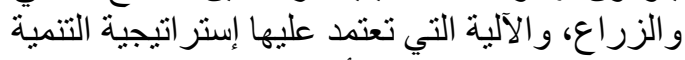

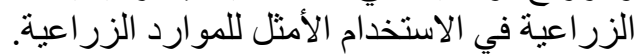

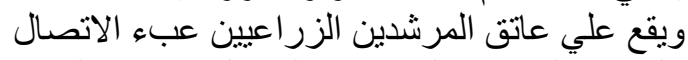

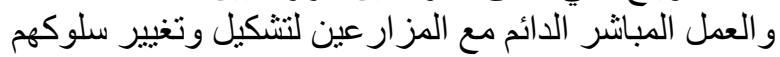

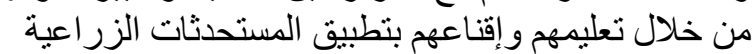

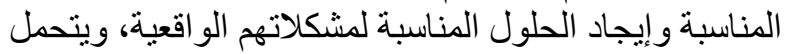

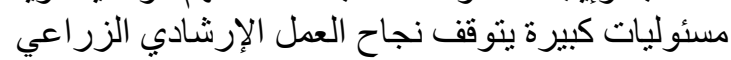

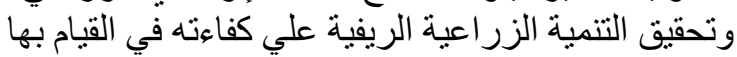
(Van,den ban\& Hawkins, 1996) ويعتبر المرشد الزر اعي حجر الزاوية في تنفيذ

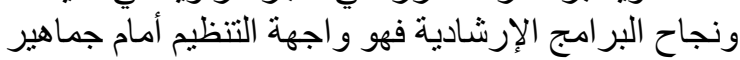

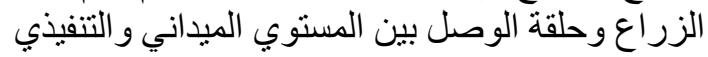
و المستويات التخطيطية بالجهاز الإرشادي.

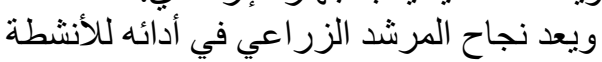

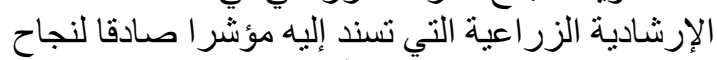

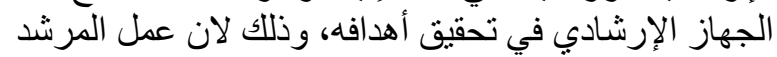

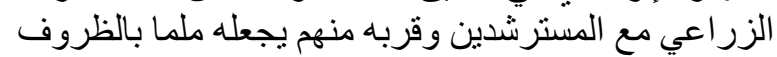

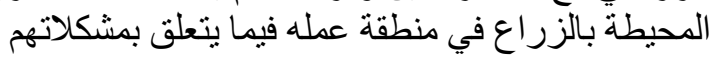

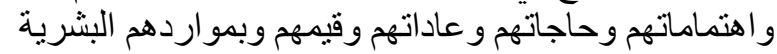
و المادية بما يضمن نجاح تخطيط وتنفيذ البر امج الإرشادية (شرشر و الصياد، 1986).

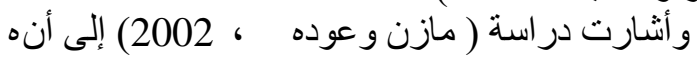

يمكن تصنيف مهام المرشد الزر اعي إند إلي المهام المرتبطة

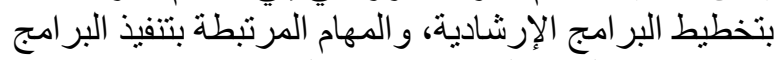

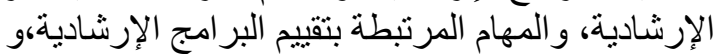
و المهام المرتبطة بحفز المسترشدين وتتشيعهم و التعامل مع التع

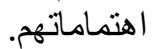




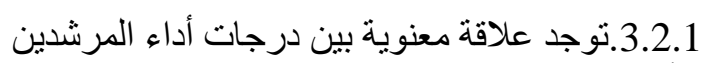

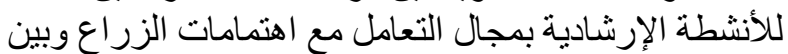
المتغير ات المستقلة المدروسة بدادة التعادية

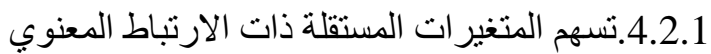

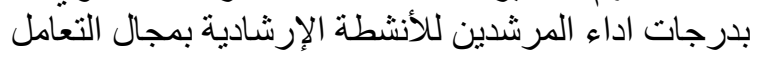

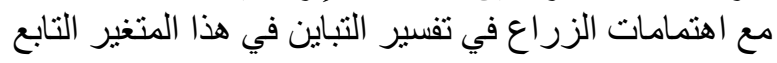

\section{2. الطريقة البحثية}

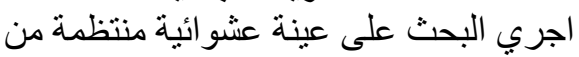

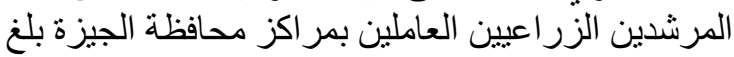

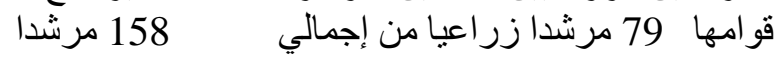

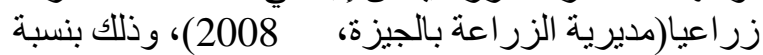

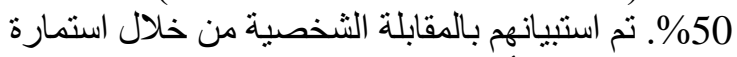

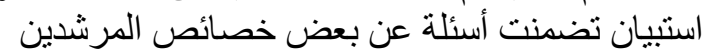

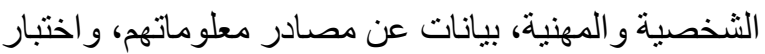

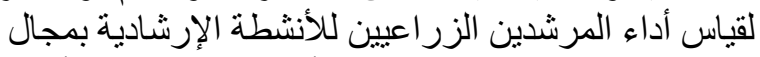

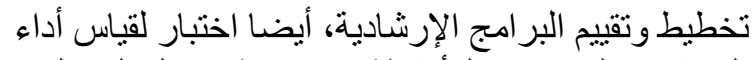

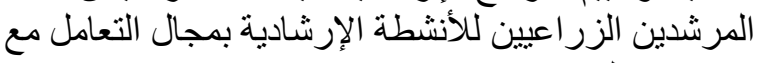

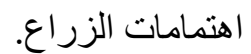

تم إجر اء اختبار مبدئي لاستمارة الاستبيان علي 15

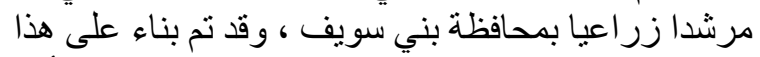

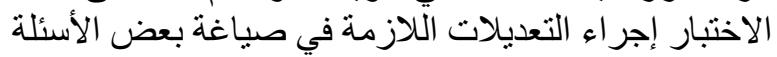

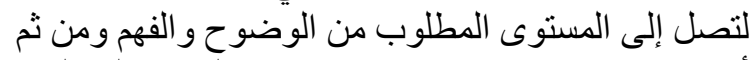

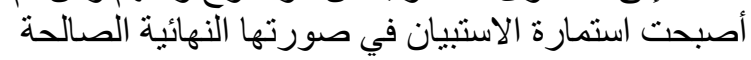

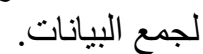

\subsection{2 المعالجة الكمية للمتغيرات المدروسة} 1.1.2 المتفيرات المستقلة الجيرة

1.1.1.2.السن: تم قياسه من خلال استخدام الأرقام الخام لسن المبحوثين بالسنة.

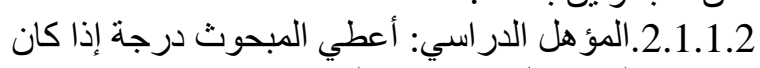

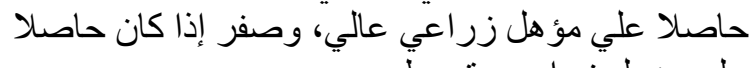
علي مؤهل زل زل ماعي منوسط.

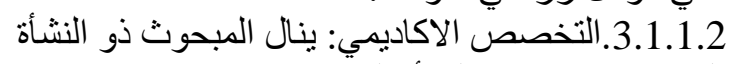
الريفية درجة، وذو النشأة الحضرية النية صفر.

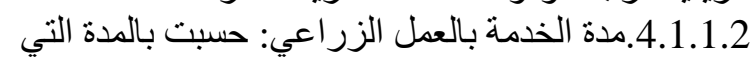

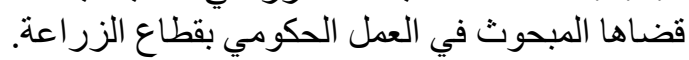

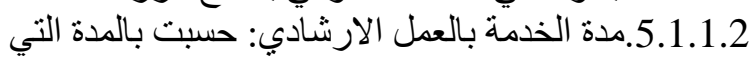
قضاها المبحوث في العمل الإرشادي.

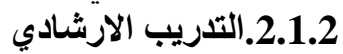

تم حسابه بعدد الدوريات التدريبية الارشادية التي حصل عليها المبحوث

3.1.2 الارجة الكلية لمصادر المعلومات

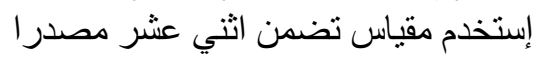

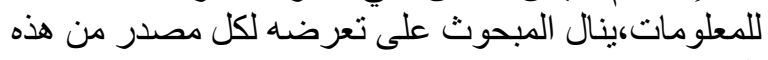

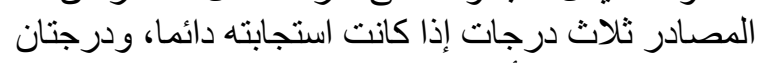

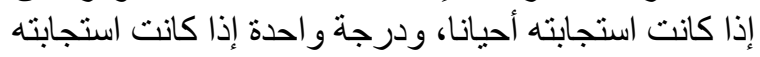

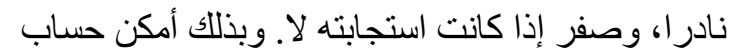

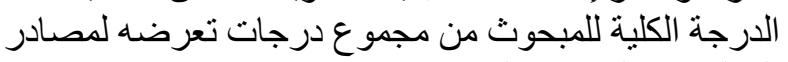
المعلومات المحددة بالمقياس.

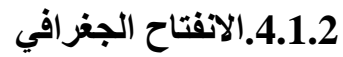

مما سبق تتضح الأهمبة الكبيرة الملقاه على كاهل

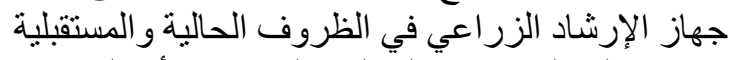

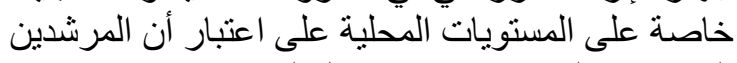

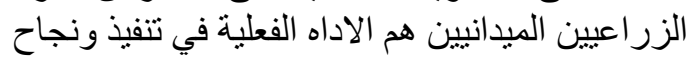

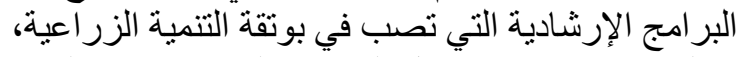

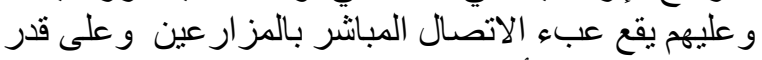

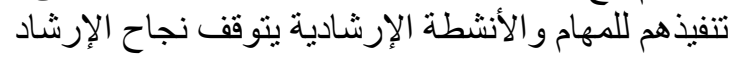

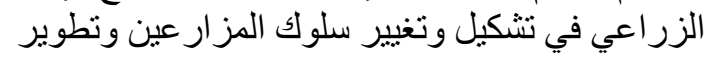

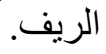

و يمكن في ضوء ذاء ذلك النظر إلى أداء المرشدين

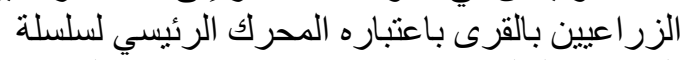

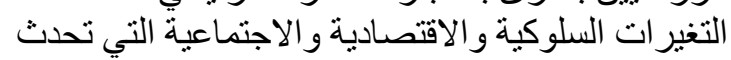

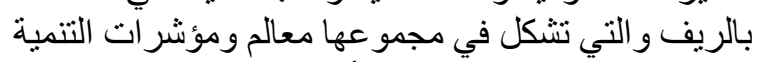

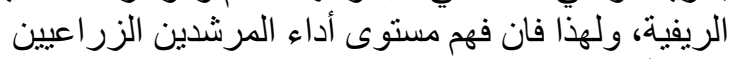

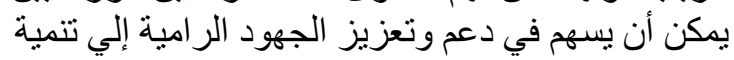

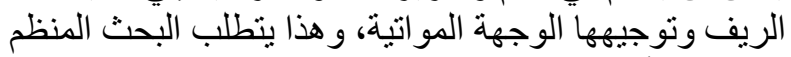

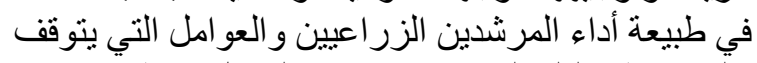

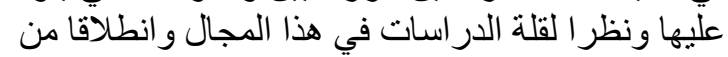

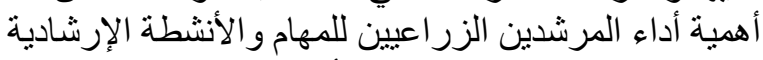

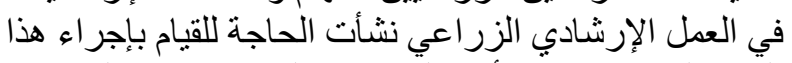

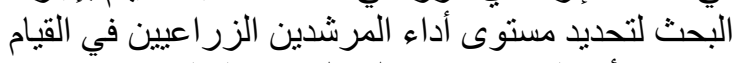

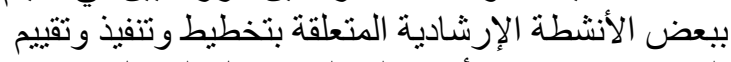

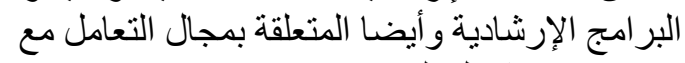

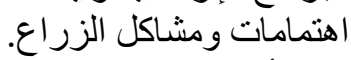

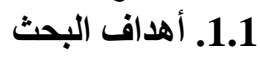

1.1.1تحديد مسنوى أداء المداء المشدين الزر اعيين للأنشطة

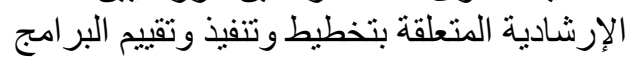
الإرشادية

2.1.1. تحديد مستوى أداء المرشدين الزر اعبين الزين للأنشطة

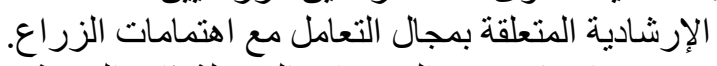

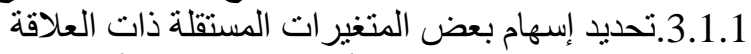

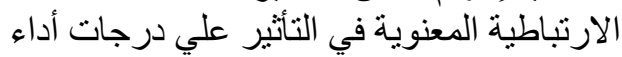

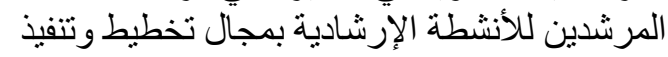
وتقييم البر امج الإرشادية الإنية

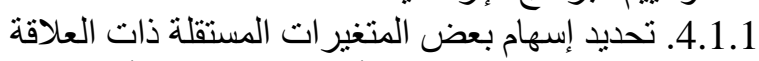

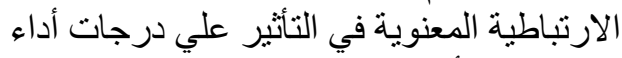

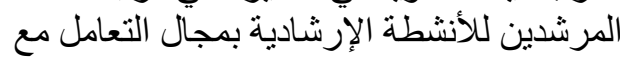

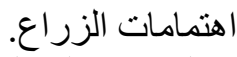
5.1.1.التعرف على الزعاعلى الزصادر التي يستقي منها المرشدين الزر اعيين معلوماتهم. 2.1.فروض البحث

لتحديد هدفي البحث البثن الثالث و الر ابع تمت صباغة الفروض البحثية التالية:

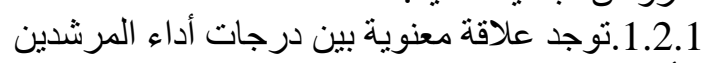

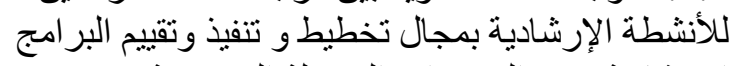

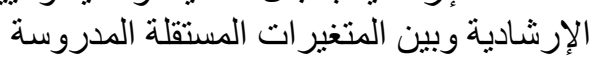

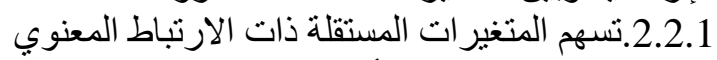

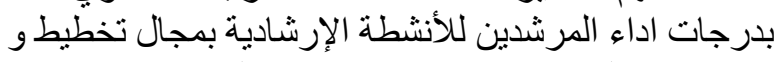

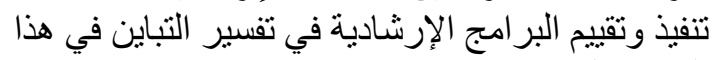

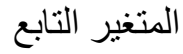


كالتالي ( مستوى أداء منخفض، مستوى أداء متوسطو

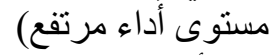
3.2 3.أدوات التحليل الإحصائي

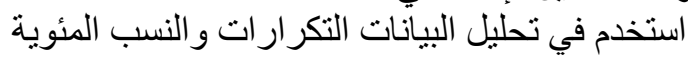

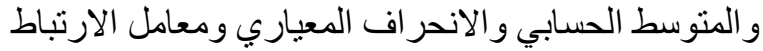

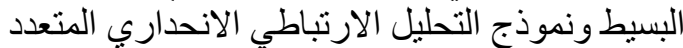

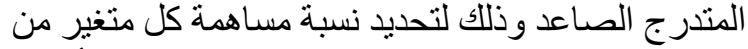

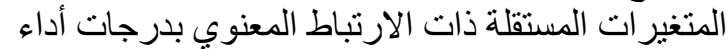

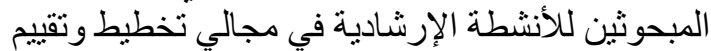

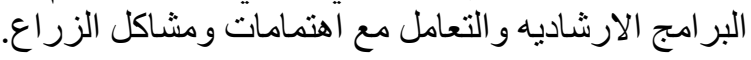

\section{3. النتائج البحثية}

1.3. درجة أداء المرشدين الزراعيين البحئة للأنشطة الإرشادية المتعلقة بتخطيط وتنفيذ وتقييم المريطية البرامج الإرشادية البرية

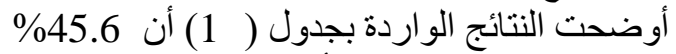

من إجمالي المبحوثين يؤدون الأنشطة الإرشادية

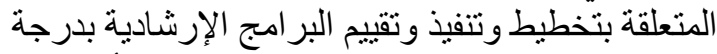

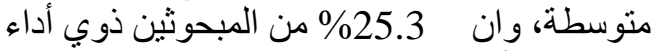

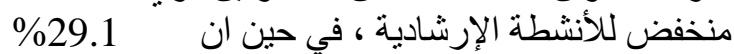

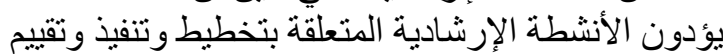

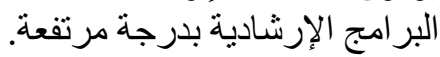

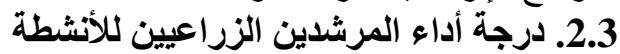

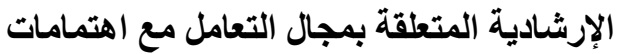

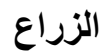

أثنارت النتائج بجدول (2) إلى أن أكثر من نصف

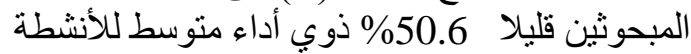

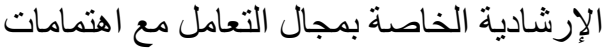

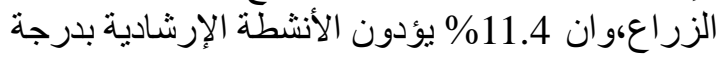

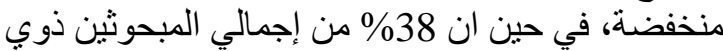

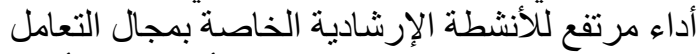

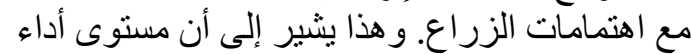

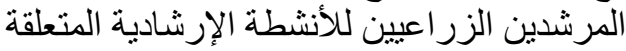

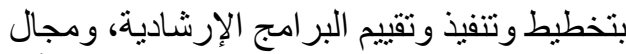

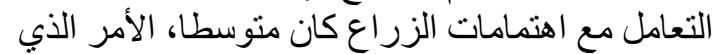
يتطلب بذل مزيد من الجهود من قبل الجهاز الزئ الإرشادي الزر اعي بمنطقة البحث في تنمية مهار ات ات أداء

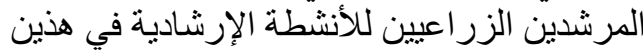

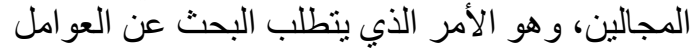

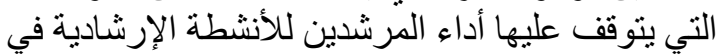

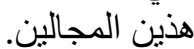

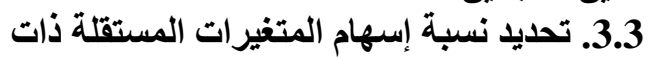

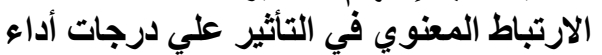

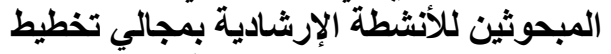

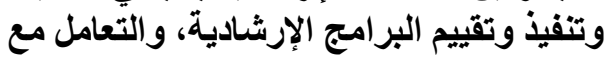

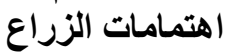

1.3.3 لتحديد المتغيرات المرتبطة معنويا بدرجات الزبات اداء

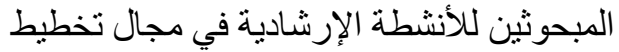
وتتفيذ وتقييم البر امج الإرشادية، تم صياغة الإنة

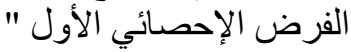

ويشمل زيارة القرى المحيطة والمركز ومر اكز أخرى أخرى

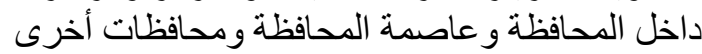

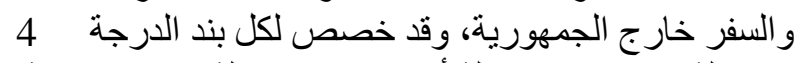

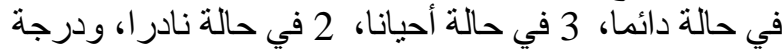

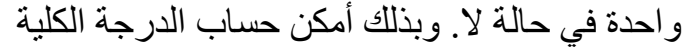

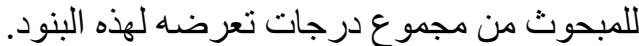
- م د درجة التنمية الذاتية

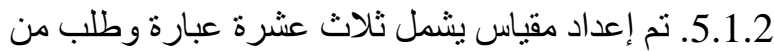

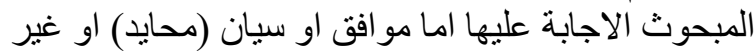

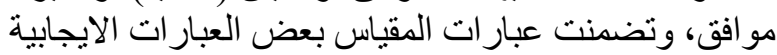

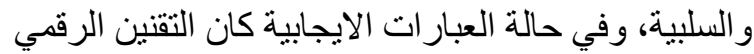

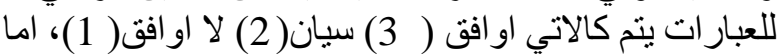

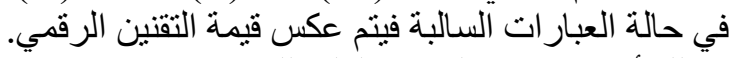

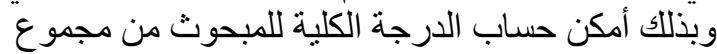
درجات تعرضها للمقياس لتعبر عن درجة التنمية الذاتية

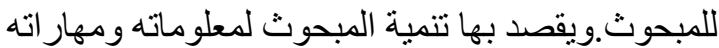
المتعلقة بالعمل الإرشادي و التعامل مع المز المعار عين وكيفية

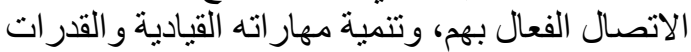
الإدارية و التنظيمية.

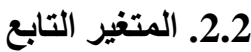

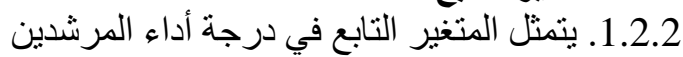

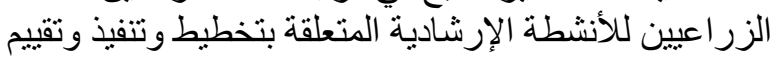

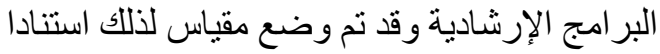

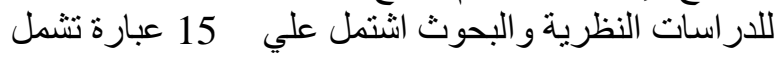

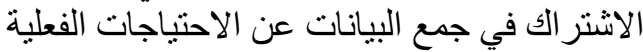

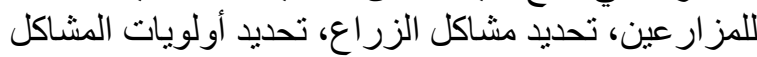

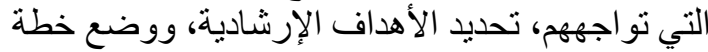

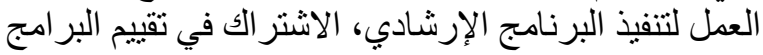

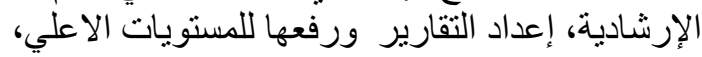

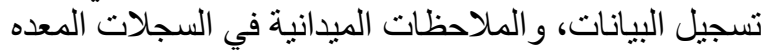

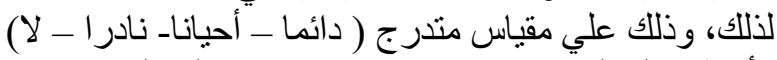

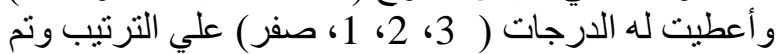

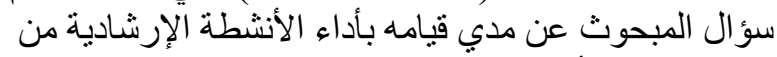

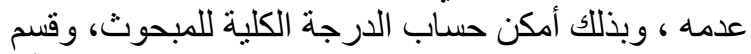

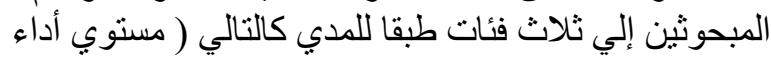

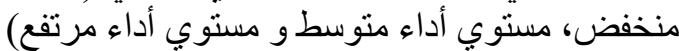
2.2.2.درجة أداء المرشدين الزر اعبين للأنشطة الإرشادية

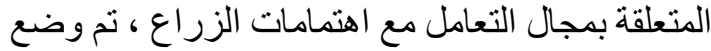

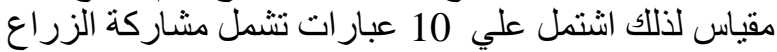

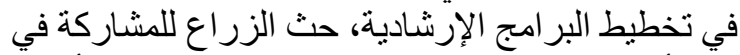

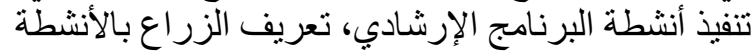

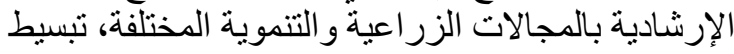

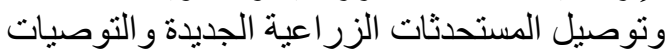

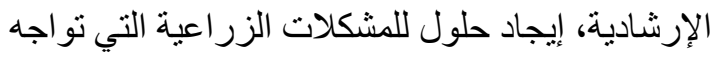

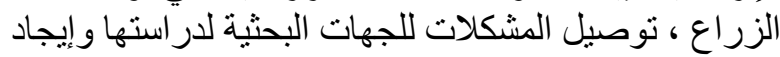

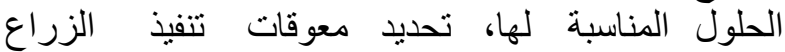

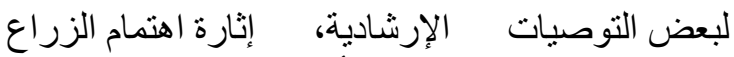

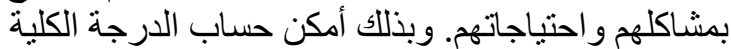
للمبحوث، وقسم المبحوثين إلي ثلاث فئات طبقان للمدي 
التو افق باستخدام قيم مربع كاي المحسوبة فكانت قيم معامل

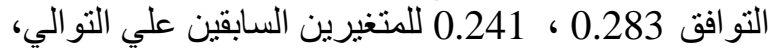

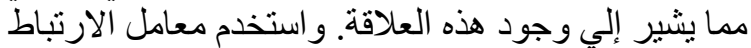

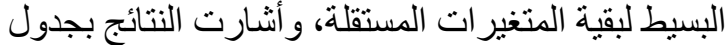

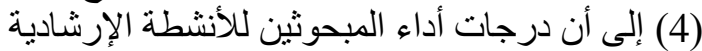

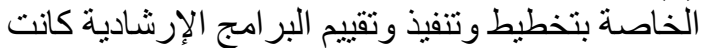

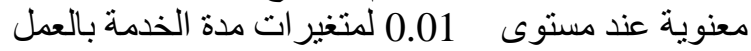

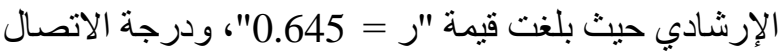

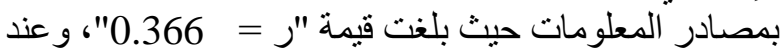
مستوى 0.05 لمتغيري التدريب الإرشادي حيث بلغي بلغت قيمة "ر = 0.215" ودرجة الانفتاح الجغرافي الإنيان

جدول (4): قيم معامل الارتباط بين درجات أداء المبحوثين

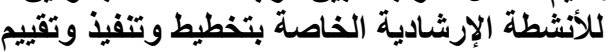

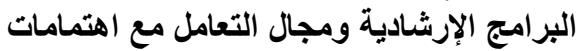

\begin{tabular}{|c|c|c|}
\hline & & الزراع \\
\hline مل الارتباط & قيم مع & المتغيرات \\
\hline 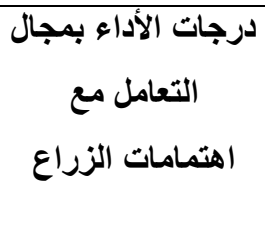 & بتخطيط وتقاصة الأداء & \\
\hline 0.149 & 0.074 & السن \\
\hline${ }^{* *} 0.339$ & 0.117 & مدة الخدمة بالقطاع \\
\hline${ }^{* *} 0.251$ & ${ }^{\star \star} 0.645$ & مدة الخدمة بالعمل \\
\hline 0.126 & ${ }^{\star *} 0.386$ & بمصادر المعلومات الاتصال \\
\hline 0.095 & 0.115 & التكريب الارشادي \\
\hline 0.117 & 0.289 & $\begin{array}{c}\text { درجة الانفتاح } \\
\text { الجغرافي }\end{array}$ \\
\hline 0.128 & 0.034 & درجة التنمية الذاتية \\
\hline
\end{tabular}

$$
\text { حيث بلغت قيمة "ر = 0.289". }
$$

ولتحديد نسبة مساهمة كل من المتغير ات المستقلة المبات

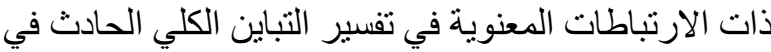

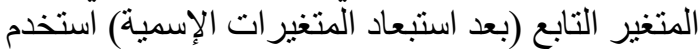

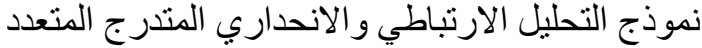

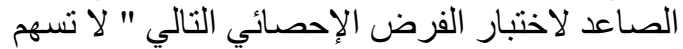

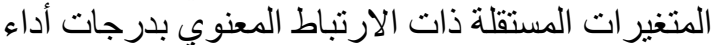

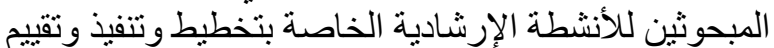

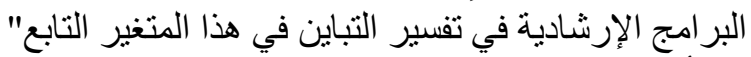

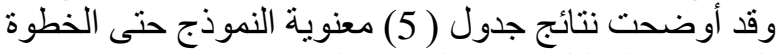

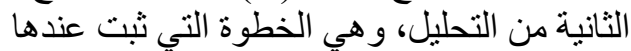
الخطأ المعياري، حيث بلغت قيمة "ف " " المحسوبة
لا توجد علاقة معنوية بين درجات اداء المبحوثين للانشطة

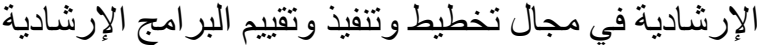
وبين المتغيرات المستقلة المدروسة"

جدول (1): أداء المبحوثين للأنثطة الإششادية الخاصة بتخطيط وتقييم البرامج الإرشادية

\begin{tabular}{|c|c|c|}
\hline \multicolumn{3}{|r|}{ وبعييم البرامب } \\
\hline$\%$ & عدد & مستوي الأداء \\
\hline 25.3 & 20 & منخفض (اقل من 20 درجة) \\
\hline 45.6 & 36 & متوسط (20-30 درجة) \\
\hline 29.1 & 23 & مرتفع ( 31 درجة فأكثر) \\
\hline 100 & 79 & الإجمالي \\
\hline
\end{tabular}

جدول ( 2): أداء المبحوثين للأنثطة الإششادية الخاصة بمجال

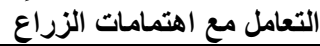

\begin{tabular}{|c|c|c|}
\hline$\%$ & عدد & مستوي الأداء \\
\hline 11.4 & 9 & منخفض (اقل من 12 درجة) \\
\hline 50.6 & 40 & متوسط (12-20 درجة) \\
\hline 38 & 30 & مرتفع (21 درجة فأكثر) \\
\hline 100 & 79 & \\
\hline
\end{tabular}

جدول ( 3): قيم مربع كاي المحسوبة بين درجات أداء

المبحوثين للأنثطة الإرشادية الخاصة بتئ بتخطيط وتتفيذ وتقييم البرامج الإرشادية ومجال التعامل مع

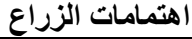

\begin{tabular}{|c|c|c|c|c|}
\hline \multicolumn{2}{|c|}{ للأنشطة الإرشادية بمجال أداء المبحوثين } & \multicolumn{2}{|c|}{ للألانثطة الإرشادية ألداء المبحوثين } & المستقلة \\
\hline التو افق & كايم مربع & التوافق & كاي & \\
\hline 0.316 & ${ }^{* *} 9.868$ & 0.241 & ${ }^{*} 7.814$ & الدراسي \\
\hline- & 1.941 & 0.283 & $\begin{array}{r}\text { * } 12.631 \\
\text { * }\end{array}$ & النشأة \\
\hline - & 0.621 & - & 2.275 & الاكاديمي \\
\hline
\end{tabular}

ولاختبار صحة هذا الفرض استخدم اختبار مربع

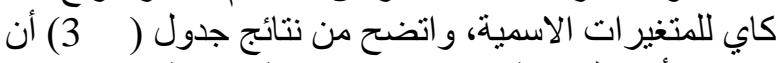
درجات أداء المبحوثين كانت ذات الات علاقة معنوية عندية

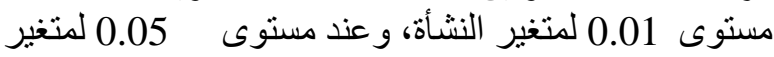
المؤهل الدراسي. ولقياس هذه العلاقة تم حساب معامل 
جدول (5): نتائج التحليل الارتباطي والاتحداري المتعدد والمتدرج الصاعد للعلاقة بين درجات أداء المبحوثين للأنثطة

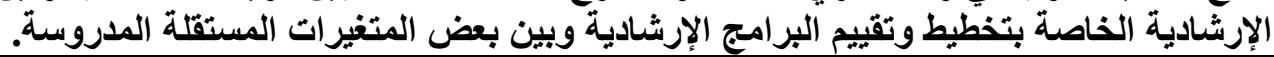

\begin{tabular}{|c|c|c|c|c|c|c|}
\hline قيمة "ت" & الجزئي القياسي الاندار & 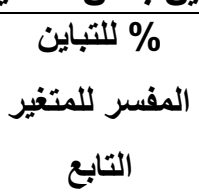 & \% المفسر للمتغير التابع للتباين & الارتباط معامل & في التخير الداخل & الخطوة \\
\hline **3.182 & 0.287 & 18.1 & 0.181 & 0.425 & بالعمل الارشادي الخذمة & 1 \\
\hline * 2.470 & 0.217 & 3.1 & 0.212 & 0.462 & لبمجة الاتصال & 2 \\
\hline
\end{tabular}

جدول (6): نتائج التحليل الارتباطي والانحداري المتعدد والمتدرج الصاعد للعلاقة بين درجات أداء المبحوثين للأنشطة

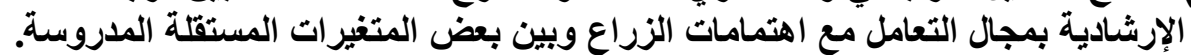

\begin{tabular}{|c|c|c|c|c|c|c|}
\hline قالمحسوبة" & الجزئي القياسي & التابعر للمتبغير & \% المفر للمتئير التتابيع & المعتعلد الارتباط & التحليل الداخل في & رقخمة \\
\hline **3.134 & 0.287 & 23.2 & 0.232 & 0.461 & مدة الخدمة بالعمل & 1 \\
\hline **3.354 & 0.267 & 4.1 & 0.316 & 0.288 & مدة الخدمة بالعمل & 2 \\
\hline
\end{tabular}

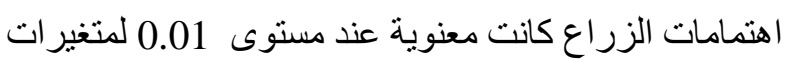

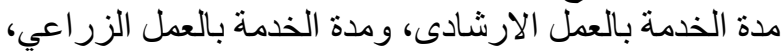

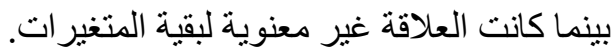

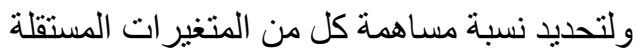

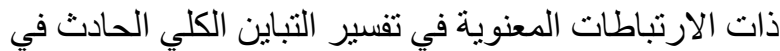

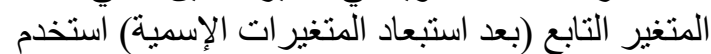

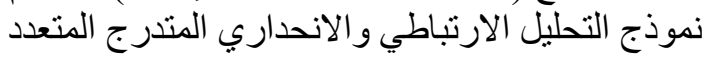

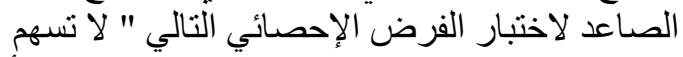

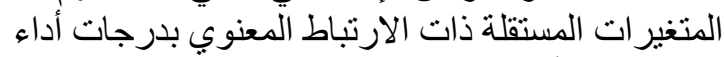

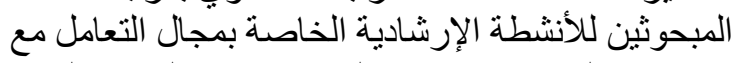

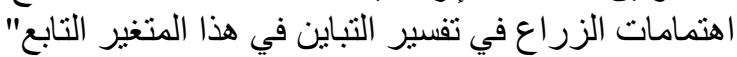

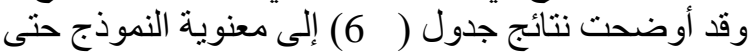

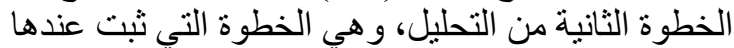

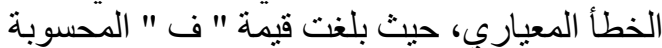

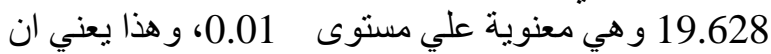
متغيرين مستقلين فقط يسهمان إسهاما معنويا في تفئير التباين في درجات أداء المبحوثين للأنشطة الإرشاديادية

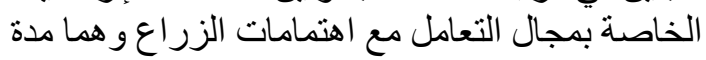

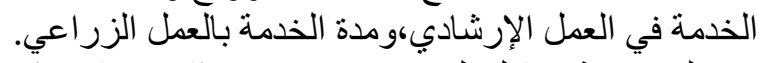

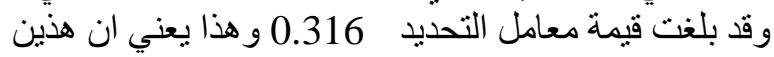
المتغيرين معا قد ساهما بنسبة 31.6\% 31.

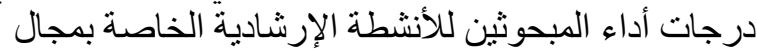

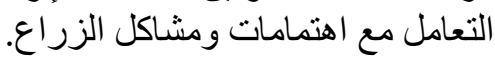
وبناءا علي النتائج السابقة يمكن القول القول بأن درجة

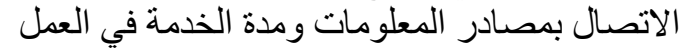

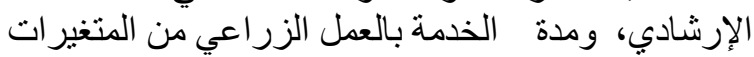

15.413 و هي معنوية علي مستوي

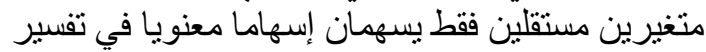
التباين في درجات أداء المبحوثين للأنشطة الإرشادية إنشاية

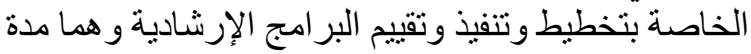

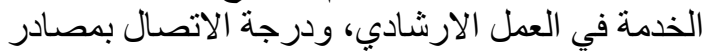

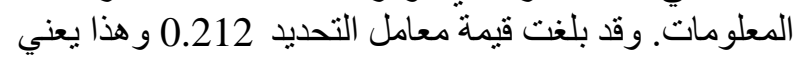

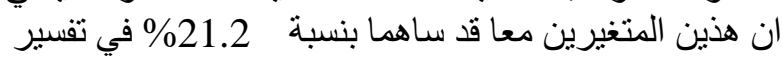
التباين في درجات أداء المبحوثين للأنشطة الإرشادية

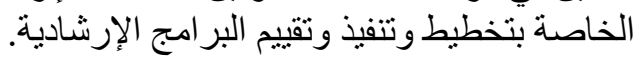

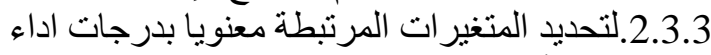

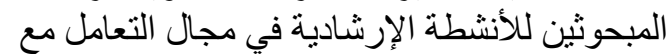

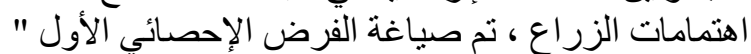

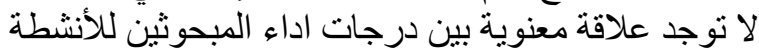

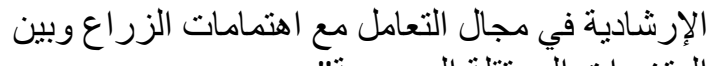

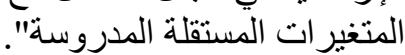

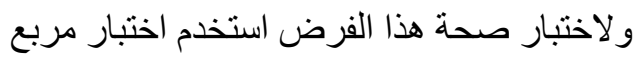

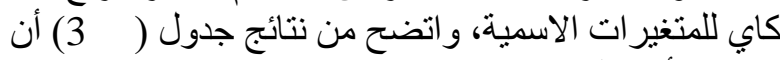

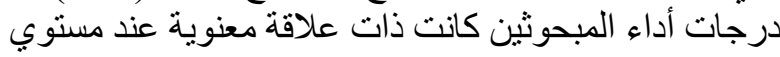
0.01

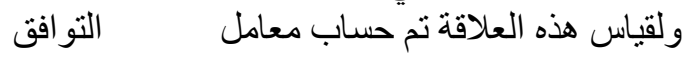

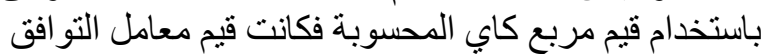
0.316 لهذا المتغير ، مما يشير إلي وجود هذه العيد العلاقة بينما

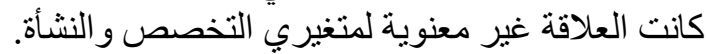

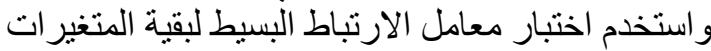

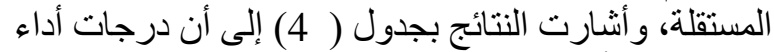

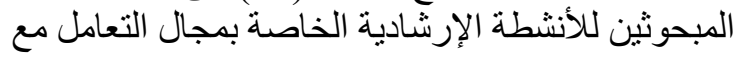




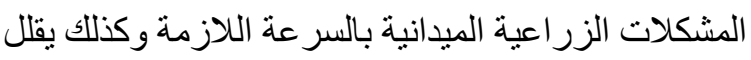

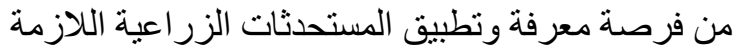

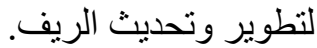

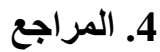

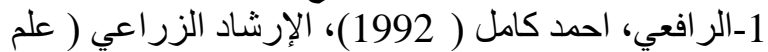

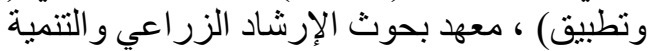

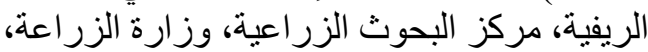
القاهرة. 2-السلمي، علي ( 1997)، إدارة الموارد البشرية، دار غريب، القاهرة. 3-النمر ،سعود بن حمحة ( 1990)، السلوك الإداري، مطابع جامعة الملك سعود، جامعة الملك سعود د.

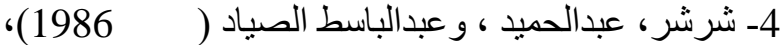

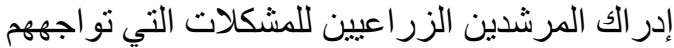
عند القيام بمهامهم الإرشادية الوظيفية لإعية بمحافظة الزئة القليوبية. مجلة الأزهر للبحوث الزئية الزر اعية، العدد

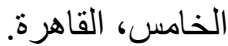

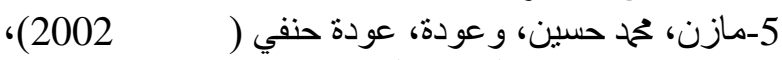

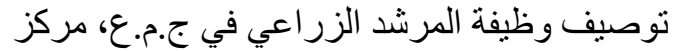
البحوث الزر اعية، المجلة المصرية للبحوث الزئه الزر اعية،

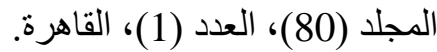

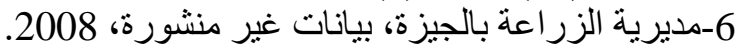

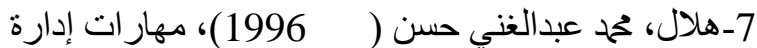

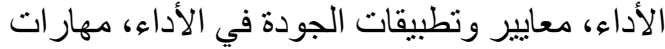
تطوير الأداء 11، الطبعة الأولي، مصردر.

\section{REFERENCES}

Chapman R. and Slamaker T. (2004). Agricultural knowledge and information, College Station, Durhan U.S.A., Vol (45).

Radhakrishna R.B., and Thomson J.S. (2007). Extension Agents, Vol 301, http/ www.joe.org.

Swanson B.E.(1984). Preservice training of extension personnel, Agricultural extension, A Reference Manual, edited by Burton E. Swanson, second edition, FAO ,Rome.

Van, den ban A.W. and Hawkins H.S.(1996). Agricultural Extension, second edition ,Blackwell, Science, INC, U.S.A.
ذات الإسهام المرتفع نسبيا في التأثير علي درجات أداء

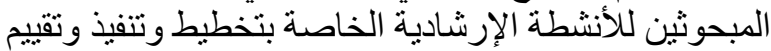

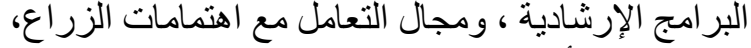

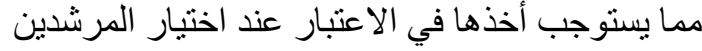
الزر اعيين للعمل في هذا المجال.

\begin{tabular}{|c|c|c|}
\hline$\%$ & عدد & المصادر \\
\hline 49.4 & 39 & النشرات الإرشادية \\
\hline 44.3 & 35 & المشرف الإرشادي \\
\hline 35.4 & 28 & الزملاء من المرشدين \\
\hline 27.8 & 22 & الكتب والمراجع العلمية \\
\hline 21.5 & 17 & مدير الإرشاد بالمديرية \\
\hline 17.7 & 14 & رؤساء الأقسام الفنية الزراعية \\
\hline 13.9 & 11 & أخصائي المادة الإرشادية \\
\hline 11.4 & 9 & الاورات التدريبية \\
\hline 10.1 & 8 & البرامج الزراعية التليفزيونية \\
\hline 6.3 & 5 & البرامج الزراعية الإذاعية \\
\hline 5.1 & 4 & مركز البحوث الزراعية \\
\hline 3.8 & 3 & كلية الزراعة \\
\hline
\end{tabular}

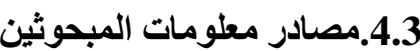

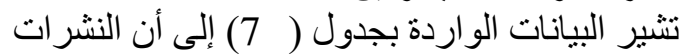

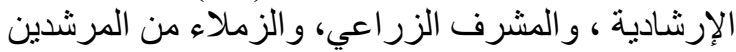

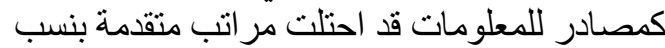

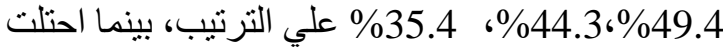

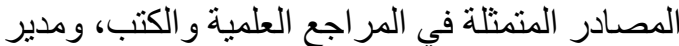
الإرشاد بمديرية الزر اعة، ورؤساء الأقسام الفنية الزر اعية العية

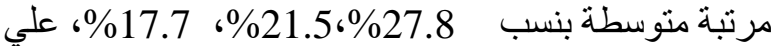
الترتيب، في حين أظهرت النتائج أن البر امج الزراعة الزية

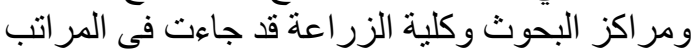

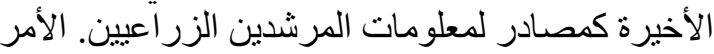

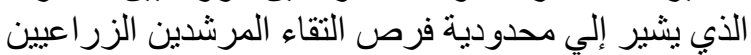
الميدانيين بالباحثين مما يقلل من فرصة مو مو اجهة وحل 